\title{
Automatic Switching of Street Light
}

\author{
Himanshu Katara
}

\begin{abstract}
This paper proposes the automatic switching of street light and reduce the electricity consumption rate up to certain limit. In the present scenario, a huge amount of electricity is wasted during the continuous illumination of street light. Therefore, this paper proposes sensor based automatic switching off and on of street light. LDR is used to detect the presence of light and turn on and off the street light accordingly. Infrared sensor is used to adjust the brightness of street light. By doing so, the power consumption rate decreases up to great extent. LEDs are used as compared to conventional street bulb due to its low cost, durability and reliability.
\end{abstract}

Keywords- Infrared (IR) sensor, LDR (Light dependent resister), Light Emitting Diode (LED).

\section{INTRODUCTION}

In today's modern world the development in transportation system plays a vital role. It consists of roads, streets, highways etc., these pathways must be illuminated brightly with the help of several types of glowing bulbs or LEDs [1]. The main purpose of providing the light to these highways, roads or street is to provide safety to the vehicle and number of persons crossing these paths and prevent them from any mis happening or accident. Another purpose of providing lighting to these places is that during the night times when a smaller number of vehicles passes the road, the pedestrian can easy crosses the roads without feeling any darkness on the road [2]. But, for providing large amount of illumination, huge amount of electricity is required which causes high cost. The main reason behind the high cost is due to the continuous glowing of lightning for more than 12 hours a day [3],[4]. So, for reducing the electricity cost and preventing the high cost there is a need to develop a system that is autonomous. Therefore, this paper deals with the system that is autonomous, it means that if there is a presence of any vehicle or person at the street, the light must be automatically turn $\mathrm{ON}$ and during the absence of any vehicles or person the light should be automatically turn OFF [5],[6].

Sometimes, it is also observed that in some places very few vehicles pass the road. In these cases, there must be automatically cut in the electricity when no vehicle passes through it and switch the electricity $\mathrm{ON}$ when vehicle passes the road. This will reduce the consumption of electricity by street lightning system by 30 to $40 \%$. Conventionally, there the street lighting systems were switched on and switched off manually with the help of some personnel which takes much human efforts and consumes high amount of electricity. [7] Hence, this paper proposes automatic switching system for street lightning. The proposed system is also effective in detecting the faults in street lightning system without actually going physically for inspection [8].

Revised Manuscript Received on 14 September, 2019.

Himanshu Katara, Department of Electronics Engineering, Sanskriti University, U.P. India.(Email: sanpubip@ gmail.com)

\section{SYSTEM DESCRIPTION}

Fig. 1 represent the block diagram of proposed system and comprises of a main power supply for providing power to the system, a sensor for detecting the presence of an object, a light dependent resistor (LDR) [9] for detecting the presence of light, a microcontroller for receiving the signal from both the sensors and control the system accordingly, a dual power supply unit for providing power to integrated chip embedded inside the micro controller and LEDs

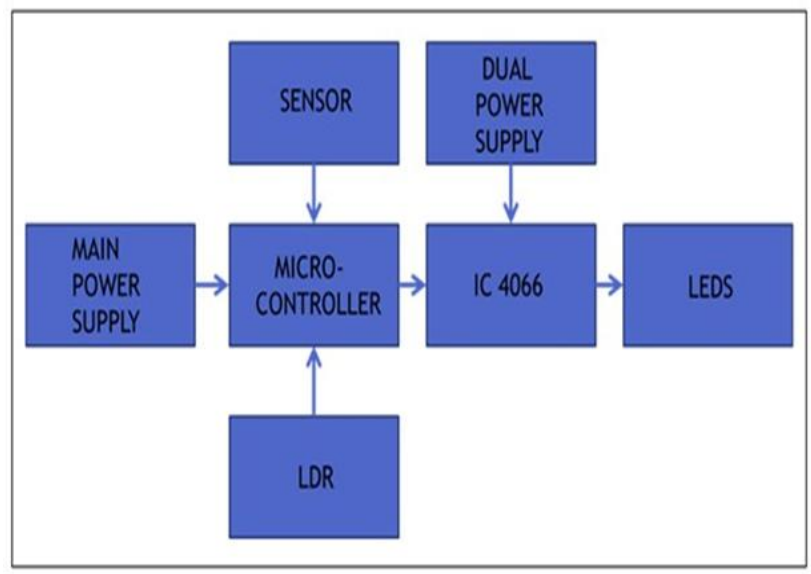

Fig.1 Block Diagram of Proposed System

The use of LED light in street lightning system instead of conventional bulb has the following advantages [10];

i. The LED has longest life as compared to the sodium bulbs.

ii. The LED takes fewer seconds to start whereas tube light takes longer time to start.

iii. The brightness of LED can be controlled very easily.

iv. It takes very less amount of power therefore reduce the energy consumption rate.

v. LED is not affected by power supply fluctuation.

The proposed system is designed in such a way that during day light time when there is no need of street light, the system will remain in turn off condition even after the system is connected to the power supply. During night time when sun is set, the LDR will sense the intensity of light and sends the signal to microcontroller for turning ON the street lightning system. When no vehicle is passing through the road then the infrared sensor that is placed on the divider of the road will detect the absence of the vehicle and sends the signal to microcontroller for dimming the brightness of street light. This technology will reduce the power consumption rate up to $60 \%$. When the sensor detects the presence of any vehicle it sends signal to microcontroller and micro controller commands to LED to glow up to its 
$100 \%$ efficiency [11]. In this system mainly two types of sensors are used which has two different function. First is Light Dependent Resistor (LDR) that is used for switching ON or switching OFF the LEDs during day and night times by detecting the intensity of light. Secondary, there is infrared sensor for detecting the presence of any vehicle passing the street. If any vehicle is detected by IR sensor than it will send the detected signal to micro controller for increasing the brightness of the street light and if no vehicle is detected by IR sensor then the micro controller will command to reduce the brightness of the street light.

Fig. 2 represents the flow diagram of the proposed system in which functions of two sensors are explained. The switching of LED is controlled by LDR sensor depending on day and night. If LDR detects day time then street light is turned off and if no light is detected i.e. during night time the street light is turn ON. After the light is turn $\mathrm{ON}$ the light intensity is controlled by infrared sensor.

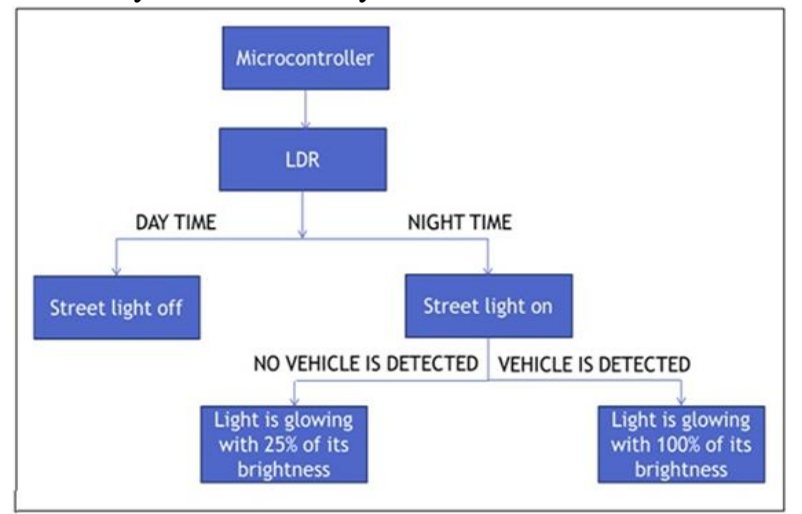

Fig.2 Flow Diagram of Proposed System

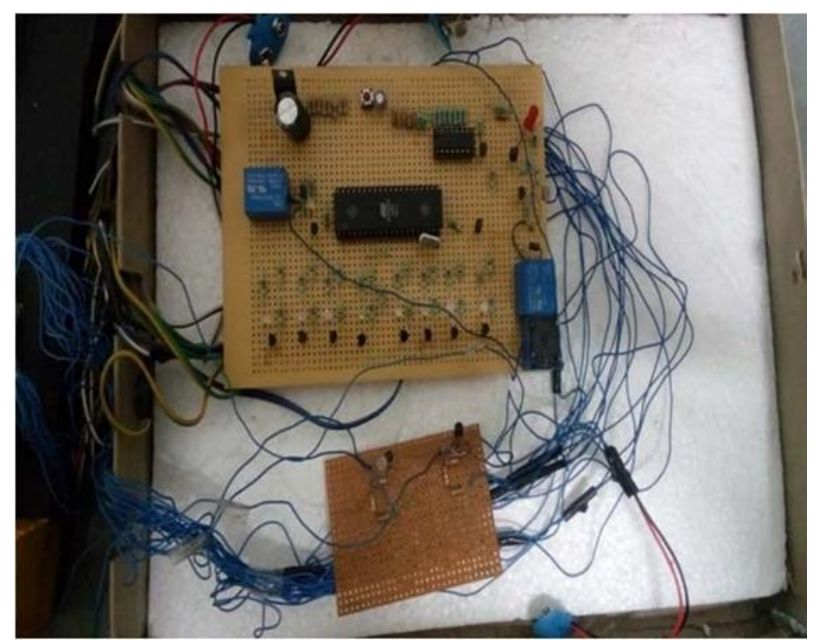

Fig.3 Circuit Diagram of Proposed System

\section{RESULT}

After designing the circuit of automatic switching street light, the prototype is practically implemented on the street. It comprises of large number of LEDs mounted on the support at certain height. IR sensor is attached on the side of the road below the street light. When any vehicle passes through the road, it sends the signal to micro controller for rising the brightness of LEDs. During absence of any vehicle the IR sensor sends signal to microcontroller for dimming the intensity of light.

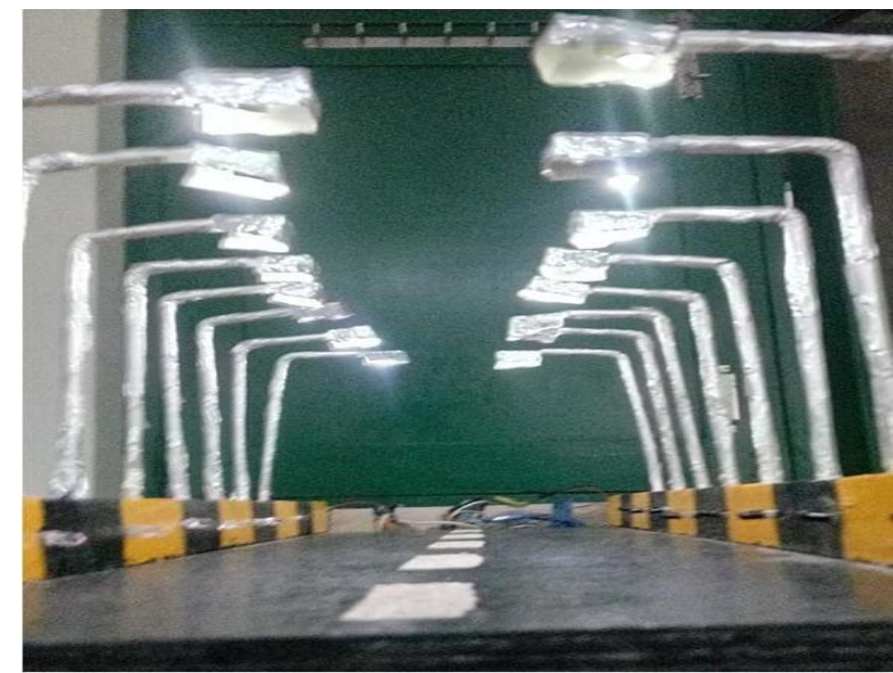

Fig.4 Prototype of Automatic Switching of Street Light

\section{CONCLUSION}

The automatic switching street light circuit is designed and the prototype is successfully implemented. In this proposed system basically two sensors are used, one is infrared sensor and other is light dependent resistor sensor. LDR sensor is used for detecting the presence of surrounding light so that during the day time when sun is bright, the street light is switched off automatically. During the night time when there is no light, the LDR sends signal to microcontroller to turn on the street light. After the light gets turn, the IR sensor adjust the brightness of the street light accordingly.

\section{REFERENCES}

1. S. Foster, H. Christian, L. Wood, and B. Giles-Corti, "PLANNING SAFER SUBURBS? THE INFLUENCE OF CHANGE IN THE BUILT ENVIRONMENT ON RESDIENTS' PERCEIVED SAFETY FROM CRIME,' Inj. Prev., 2012.

2. F. R. Beyer and K. Ker, "Street lighting for preventing road traffic injuries," Cochrane Database of Systematic Reviews. 2009

3. B. Kempenaers, P. Borgström, P. Loës, E. Schlicht, and M. Valcu, "Artificial night lighting affects dawn song, extra-pair siring success, and lay date in songbirds," Curr. Biol., 2010.

4. F. R. Beyer and K. Ker, "Street lighting for prevention of road traffic injuries," Inj. Prev., 2009.

5. S. P. Lau, G. V. Merrett, A. S. Weddell, and N. M White, "A traffic-aware street lighting scheme for Smart Cities using autonomous networked sensors," Comput. Electr. Eng., 2015.

6. N. N. Bakin, V. I. Tuyev, and E. F. Yauk, "LED lighting," in 12th International Conference and Seminar on Micro/Nanotechnologies and Electron Devices, EDM'2011 - Proceedings, 2011.

7. Y. A. Badamasi, "The working principle of an Arduino," in Proceedings of the 11th International Conference on Electronics, Computer and Computation, ICECCO 2014 2014.

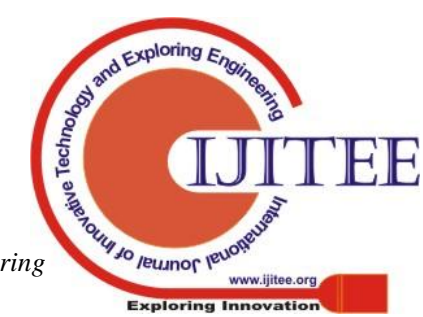


8. M. Saad, A. Farij, A. Salah, and A. Abdaljalil, "Automatic street Light Control System using Microcontroller," Math. Methods Optim. Tech. Eng., 2013.

9. E. Efficiency, E. Circuit, L. Dependent, and R. Circuits, "Light dependent resistor (ldr)," Energy, 2010.

10. T. Pulli, T. Dönsberg, T. Poikonen, F. Manoocheri, P. Kärhä, and E. Ikonen, "Advantages of white LED lamps and new detector technology in photometry," Light Sci. Appl., 2015.

11. D. P. Farrington and B. C. Welsh, "Effects of improved street lighting on crime: a systematic review," Campbell Syst. Rev., 2008. 